\title{
A 3-year study of high-cost users of health care
}

\author{
Walter P. Wodchis PhD, Peter C. Austin PhD, David A. Henry MBChB \\ Infographic available at www.cmaj.ca/lookup/suppl/doi:10.1503/cmaj.150064/-/DC2
}

Competing interests: None declared.

This article has been peer reviewed.

Accepted: Oct. 27, 2015

Online: Jan. 11, 2016

Correspondence to:

Walter Wodchis,

walter.wodchis@utoronto.ca

CMAJ 2016. DOI:10.1503

/cmaj.150064

\begin{abstract}
Background: Characterizing high-cost users of health care resources is essential for the development of appropriate interventions to improve the management of these patients. We sought to determine the concentration of health care spending, characterize demographic characteristics and clinical diagnoses of high-cost users and examine the consistency of their health care consumption over time.
\end{abstract}

Methods: We conducted a retrospective analysis of all residents of Ontario, Canada, who were eligible for publicly funded health care between 2009 and 2011. We estimated the total attributable government health care spending for every individual in all health care sectors.

Results: More than $\$ 30$ billion in annual health expenditures, representing $75 \%$ of total government health care spending, was attributed to individual costs. One-third of high-cost users (individuals with the highest $5 \%$ of costs) in 2009 remained in this category in the subsequent 2 years. Most spending among high-cost users was for institutional care, in contrast to lower-cost users, among whom spending was predominantly for ambulatory care services. Costs were far more concentrated among children than among older adults. The most common reasons for hospital admissions among high-cost users were chronic diseases, infections, acute events and palliative care.

Interpretation: Although high health care costs were concentrated in a small minority of the population, these related to a diverse set of patient health care needs and were incurred in a wide array of health care settings. Improving the sustainability of the health care system through better management of highcost users will require different tactics for different high-cost populations.
$\mathrm{H}$ ealth care spending per person in any given year is highly uneven. The concentration of health care utilization among small numbers of patients is well established. In the United States, the Agency for Healthcare Research and Quality reported that $1 \%$ of users in 2008 accounted for $20 \%$ of expenditures and that $5 \%$ of users accounted for nearly $50 \%$ of expenditures. ${ }^{1}$ Data from Canada in 1972 and 1996, and again in 2009, showed that high-cost users (individuals with the highest $5 \%$ of costs) consumed $65 \%$ of combined hospital and nursing home costs, $64 \%$ of acute care days and $84 \%$ of combined acute and post-acute home care resources, respectively. ${ }^{2-4}$

Each year, a few people have major health events that must be addressed, often with expensive treatments. The relative rarity and unpredictability of these events for any individual underlies the need for health care insurance. However, improved life expectancy, resulting in part from effective treatments of cardiovascular and respiratory disease, HIV infection and some cancers, ${ }^{5}$ as well as the chronic debilitating effects of conditions, such as severe stroke or heart failure, are contributing to rising numbers of chronically high users of health care resources. Yet, little is known about the sustained use of health care services among high-cost users.

Previous studies of high-cost users in the US have been limited by the use of survey respondents as a source population ${ }^{1}$ or included only patients in private insurance systems who were less than 65 years of age. ${ }^{6,7}$ Studies in Canada have examined spending on acute hospital, physician or nursing home care only, representing less than half of all health care expenditures.,3 Age-related patterns have not been compared.

We conducted a study to make a system-wide assessment of the concentration and persistence of costs in a comprehensive health care system. We had several objectives: to measure total expenditures of publicly insured care for every individual, and by health care sector, in the province of Ontario between 2009 and 2011; to track expenditure patterns for individuals over a 3-year period; to 
describe the concentration of health care spending among different age groups; and to identify the main diagnoses among high-cost users.

\section{Methods}

\section{Population}

In Ontario, the costs of all medically necessary care, both acute and long term, are covered for all residents by public health insurance funded from general taxation. Our raw study population consisted of 14.9 million people with a recorded age of less than 105 years who were alive on Apr. 1 in any of the 3 study years $(2009,2010$ or 2011) and who had a valid Ontario health card at any time between Apr. 1, 2009, and Mar. 31, 2012. For longitudinal analyses, we included only people who were alive on Apr. 1, 2009, and followed them forward for 3 years. For cross-sectional analyses, we included only those who were alive on Apr. 1, 2011.

\section{Data}

All of the data used in our study were from the Institute for Clinical Evaluative Sciences (ICES). The study received ethics approval by the Sunnybrook Health Sciences Review Board. Individuals for the study population were identified from the Ontario Registered Persons Database. In addition to insurance eligibility, this database provides basic demographic information on each eligible resident of Ontario.

Administrative databases, linked securely and anonymously at the level of each eligible resident, were used to track all health service encounters paid for by the Ontario Ministry of Health and Long-Term Care. We tracked admissions to hospitals using the Canadian Institute for Health Information's Discharge Abstract Database, Continuing Care Reporting System, National Rehabilitation Reporting System, National Ambulatory Care Reporting System and Ontario Mental Health Reporting System. We tracked physician visits, including fee-for-service visits and shadow-billed services, as well as laboratory claims using Ontario Health Insurance Plan billings. The Home Care Database was used to measure all unique visits by home care providers, and the Ontario Drug Benefit Plan identified prescriptions dispensed to people eligible for social assistance and those aged 65 years or more. People living in long-term care facilities were identified based on prescriptions or physician visits that included a long-term care resident flag. ${ }^{8}$

\section{Costs}

In this analysis, the term "cost" refers to health care expenditures that have been allocated to patient encounters for health care. We deter- mined nominal costs for each encounter with the health care system using algorithms that have been implemented at ICES and are based on costing methods using administrative data. ${ }^{9}$

Patient-level costs for each encounter where an encounter-specific payment was made (e.g., for prescriptions or fee-for-service physician visits) used the fee paid for the service. Costs for hospital encounters used the appropriate resource intensity weight for that particular care setting multiplied by the applicable cost amount based on Ontario spending. ${ }^{9}$ Costs for long-term care were measured as a fixed per diem based on prevailing government payment rates. Emergency physicians and oncologists receive substantial alternative payments that are not visit-related, and the algorithms ascribed these payments, generally by allocating the payments as an average amount for each patient seen by these providers. Capitation payments were calculated based on the payment rate and the particular model of primary care for each patient's physician in each month of the study period. Data on alternate payment plans (e.g., academic centre payments and capitation arrangements in primary care) were also accessed to provide a complete picture of physician payments. ${ }^{10}$

We excluded costs for services that are not reported using patient-specific encounter data. Team-based payments for family health teams, physician pay-for-performance and salaried physician services are examples of services not reported with patient-level identifiers.

We used 5 categories to report costs: acute hospital (including emergency department), other hospital, continuing care (including longterm care and home care), physician, and drugs and laboratory costs outside of hospitals.

\section{Statistical analysis}

We tracked every encounter within each fiscal year (Apr. 1 to Mar. 31), and for every individual, using all of the health administrative databases described earlier. Using nominal costs (i.e., amounts paid in the fiscal year), we calculated total costs associated with all utilization within each fiscal year for each eligible resident alive at the start of the year. Costs for care episodes that spanned more than one fiscal year were divided on a pro rata basis between the 2 years. We then sorted the entire database of unique individuals according to total health care cost for each person separately for each year. We identified people who accounted for the top $1 \%, 5 \%, 10 \%$ and $50 \%$ of costs in this distribution.

To identify how many remained high-cost users in successive years, we studied how people transitioned into and out of the percentile bands each year. To do this, we identified the costs in 
each of the 3 study years for each person alive on Apr. 1, 2009, and grouped them as being above the 95th or the 90th percentile, between the 50th and 89th percentiles, or below the 50th percentile of costs. We tracked which percentile band the person belonged to in 2009, 2010 and 2011, and whether they died or lost eligibility for public health insurance.

To describe further the characteristics and health care utilization patterns of high-cost users, we explored the composition of expenditures across health care sectors by decile of cost and contrasted these results for the total study population and for people in the top $1 \%$ cost group. We then examined age-specific costs, health care utilization and clinical conditions. In addition, we identified the cost threshold associated with the top $1 \%, 5 \%, 10 \%$ and median costs for each of 3 subpopulations: children $(<18 \mathrm{yr})$, adults $(18-64$ yr) and older adults (65-105 yr) based on their age on Apr. 1, 2011. The total cost for all care in each stratum (e.g., top $1 \%$ or top $5 \%$ ) was calcu- lated to measure the proportion of total health care spending associated with each threshold. Age-specific results were based exclusively on people in that age group.

Finally, we examined the primary diagnoses for acute hospital admissions (using ICD-10 [International Statistical Classification of Diseases and Related Health Problems, 10th revision] codes) among people in the top $1 \%$ cost group in each age group (based on age-specific spending) and the health care utilization patterns of acute and other care sectors among people in the top $1 \%$ in each age group. We performed these cross-sectional analyses using data from the final study year.

\section{Results}

Transitions between cost strata by year

Table 1 summarizes the trajectories across the 3 years according to the cost group for each person in 2009 and in each subsequent study year. The dominant pattern was stability in each cost group

\begin{tabular}{|c|c|c|c|c|c|}
\hline \multirow{2}{*}{$\begin{array}{l}2009 \\
\text { population }\end{array}$} & \multicolumn{3}{|c|}{ Cost category per year, percentile } & \multirow[b]{2}{*}{ Population } & \multirow{2}{*}{$\begin{array}{c}\% \text { of } 2009 \\
\text { population }\end{array}$} \\
\hline & 2009 & 2010 & 2011 & & \\
\hline \multirow[t]{6}{*}{710922} & $\geq 95$ th & $\geq 95$ th & $\geq 95$ th & 218342 & 30.7 \\
\hline & $\geq 95$ th & $\geq 90$ th in both years & & 99670 & 14.0 \\
\hline & $\geq 95$ th & $\geq 90$ th in one year, $<$ & in the other & 107778 & 15.1 \\
\hline & $\geq 95$ th & $<90$ th in both years & & 166078 & 23.3 \\
\hline & $\geq 95$ th (died)§ & - & - & 65019 & 9.1 \\
\hline & $\geq 95$ th & Any (died)§ & - & 54035 & 7.5 \\
\hline \multirow[t]{5}{*}{711039} & 90th-94th & $\geq 90$ th in both years & & 203654 & 28.6 \\
\hline & 90th-94th & $\geq 90$ th in one year, $<$ & in the other & 163136 & 22.9 \\
\hline & 90th-94th & $<90$ th in both years & & 325805 & 45.7 \\
\hline & 90th-94th (died)§ & - & - & 7017 & 1.0 \\
\hline & 90th-94th & Any (died)§ & - & 11427 & 1.6 \\
\hline \multirow[t]{5}{*}{5687157} & 50th-89th & $\geq 90$ th in both years & & 187872 & 3.3 \\
\hline & 50th-89th & $\geq 90$ th in one year, $<$ & in the other & 776559 & 13.6 \\
\hline & 50th-89th & $<90$ th in both years & & 4691878 & 82.3 \\
\hline & 50th-89th (died)§ & - & - & 11916 & 0.2 \\
\hline & 50th-89th & Any (died)§ & - & 18932 & 0.3 \\
\hline \multirow[t]{5}{*}{7087908} & $<50$ th & $\geq 90$ th in both years & & 20092 & 0.3 \\
\hline & $<50$ th & $\geq 90$ th in one year, & in the other & 247469 & 3.5 \\
\hline & $<50$ th & $<90$ th in both years & & 6810888 & 95.6 \\
\hline & $<50$ th (died)§ & - & - & 4350 & 0.1 \\
\hline & $<50$ th & Any (died)§ & - & 5109 & 0.1 \\
\hline $\begin{array}{l}\text { *Totals in pop } \\
\text { +Percentages } \\
\text { fln this second } \\
\geq 95 \text { th percent } \\
\text { §Cost category }\end{array}$ & $\begin{array}{l}\text { lation are less than those } \\
\text { e based on the } 2009 \text { pop } \\
\text { row, one year is } 90 \text { th- } 94 \\
\text { e in all } 3 \text { years is separat } \\
\text { shown for year of death }\end{array}$ & $\begin{array}{l}\text { in Appendix } 1 \text { because nor } \\
\text { ulation total in the same ce } \\
\text { h percentile and other yea } \\
\text { d out for this group only. } \\
\text { ollowed by "-" in subsequ }\end{array}$ & $\begin{array}{l}\text { le patients are } n \\
\text { egory. } \\
\text { be either } 90 \text { th- } \\
\text { ars. }\end{array}$ & $\begin{array}{l}\text { t represented in } \\
\text { th or } \geq 95 \text { th per }\end{array}$ & $\begin{array}{l}\text { is table. } \\
\text { tile, because }\end{array}$ \\
\hline
\end{tabular}


over all 3 study years. About $45 \%$ of people above the 95th percentile in 2009 stayed at high or very high cost levels (above the 90th percentile) in both 2010 and 2011; a further 15\% dipped below the 90th percentile in only one subsequent year. Nine percent died in the second study year and $7.5 \%$ in the third year. Similarly, about $51 \%$ of those who were in the 90th-94th percentile cost category in 2009 stayed at or above this level in both of the subsequent years. Among individuals whose costs were in the 90th-94th percentile in 2009 and subsequently dropped below the 90th percentile in either 2010 or 2011, about two-thirds remained above the 50th percentile in both subsequent years. Of those with moderate costs (between the 50th and 89th percentiles) in $2009,82.3 \%$ remained at or below this level, and $13.6 \%$ moved into a higher cost category in only one of the subsequent years. Of people in the lowest cost group ( $<50$ th percentile) in 2009, nearly $96 \%$ remained below the 90 th percentile in both subsequent years, $3.5 \%$ had one year of spending above the 90th percentile, and $0.3 \%$ became high-cost users in both subsequent years. The full data, with more than 250 specific possible transitions between cost groups across the 3 years, are included in Appendix 1 (available at www.cmaj.ca/ lookup/suppl/doi:10.1503/cmaj.150064/-/DC1).

\section{Cost distribution across health care sectors}

Figure 1 shows how expenditures by health care sector in 2011/12 varied across deciles of cost. The most striking feature in the lower deciles is that costs were almost entirely for physician services, with gradually increasing expenditures for medications and laboratory work. Acute hospital care accounted for more than $10 \%$ of costs only from the fifth decile upward (and that was primarily for emergency department care until the eighth decile [data not shown]). In the top decile, a diverse range of health care sectors generated costs, with other hospital and continuing care becoming strong drivers.

Figure 2 shows the cost distribution across health care sectors in 2011/12 for the total study population, for people in the top $1 \%$ cost group and for those in the top $1 \%$ without acute care costs. The last subgroup was identified after observing that nearly $40 \%$ of people in the top $1 \%$ did not have acute care utilization (Appendix 2, available at www.cmaj.ca/lookup/suppl/doi:10.1503/cmaj. 150064/-/DC1). For the total study population, physician services accounted for $27 \%$ of total expenditures, and continuing care accounted for $15 \%$. In contrast, in the top $1 \%$ cost group, physician services accounted for $9 \%$ and continuing care for $26 \%$ of total expenditures. In the top $1 \%$ cost group without acute care, continuing care accounted for about half of all expenditures.

\section{Cost distribution by age group}

The concentration of health care costs in 2011/12 differed markedly across the 3 age groups (Figure 3). Children in the top $1 \%$ and $5 \%$ cost groups accounted for $38 \%$ and $59 \%$ of total expenditures, respectively, in that age group. Among adults 65 and older, those in the top $1 \%$ and $5 \%$ cost groups accounted for only $16 \%$ and $44 \%$ of total expenditures, respectively,

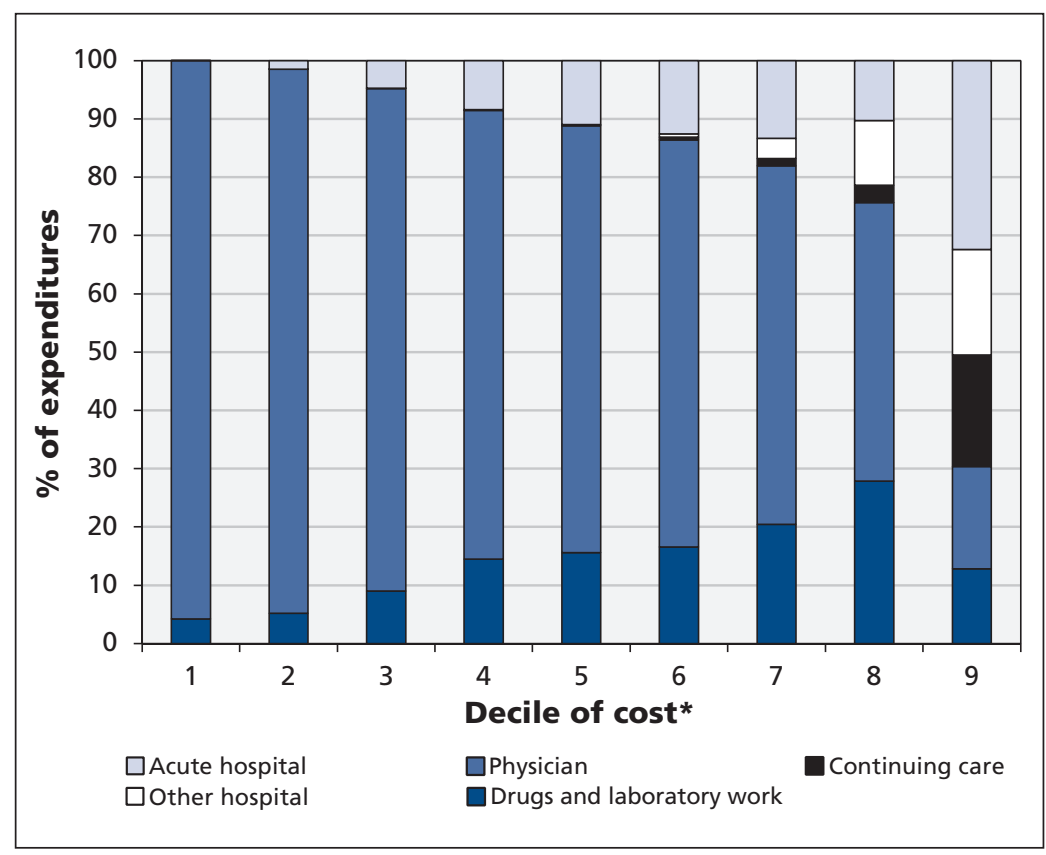

Figure 1: Cost distribution across health care sectors in 2011/12, by deciles of cost. * Lowest decile with no spending omitted.

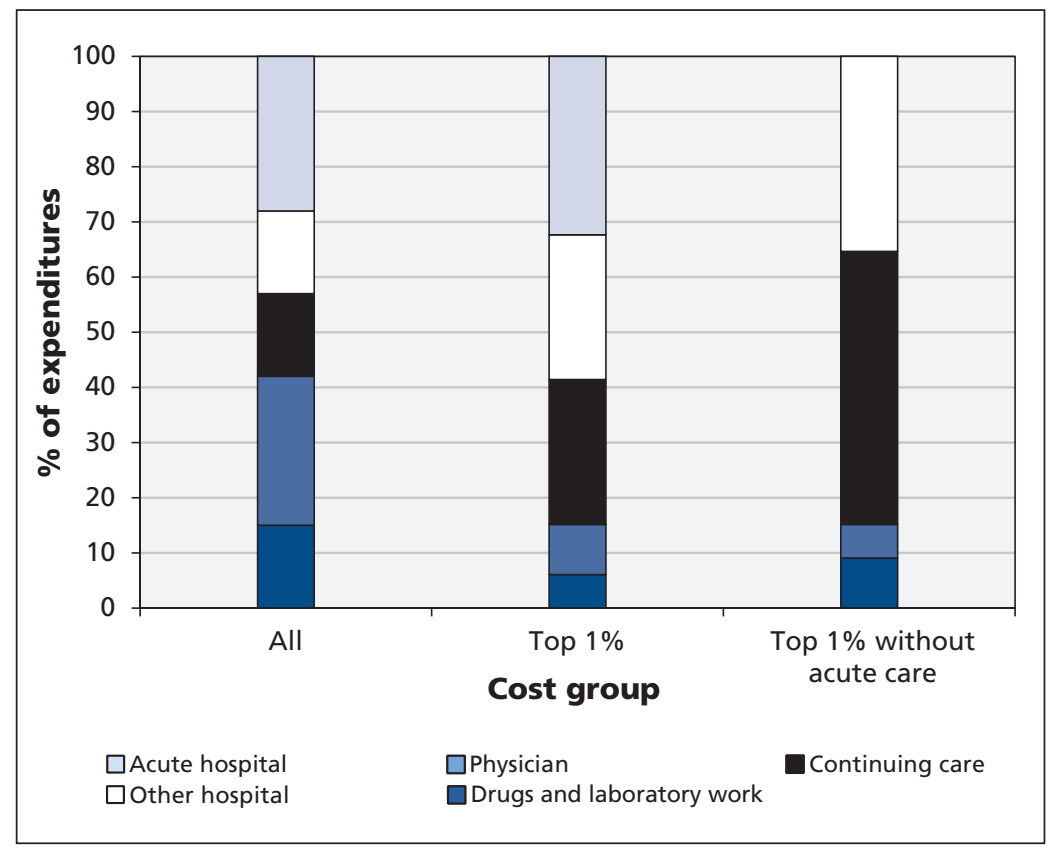

Figure 2: Cost distribution across health care sectors in 2011/12 for the total study population, for people in the top $1 \%$ cost group and for those in the top $1 \%$ cost group who had no acute care costs. 
in that age group. The cost threshold for the top $1 \%$ also varied considerably across age groups (Table 2), with children having a threshold that was about one-tenth that of the oldest group (\$8383 v. $\$ 83$ 039). The cost threshold for the median category also varied, from $\$ 195$ among children to $\$ 2211$ among the older adults.

We calculated comparable results for the total population. The larger number of individuals in the children and adult groups were strong drivers of the population results: $1 \%$ of the population accounted for $33 \%$ of costs, with a threshold of $\$ 44906 ; 5 \%$ accounted for $65 \%$ of costs, with a threshold of $\$ 7961 ; 10 \%$ accounted for $77 \%$ of costs, with a threshold of $\$ 3815$; and half of the population with median annual costs of $\$ 333$ or higher accounted for $98 \%$ of all allocated expenditures.

\section{Clinical considerations}

We examined the most responsible diagnosis for acute care admissions in the top $1 \%$ cost group in

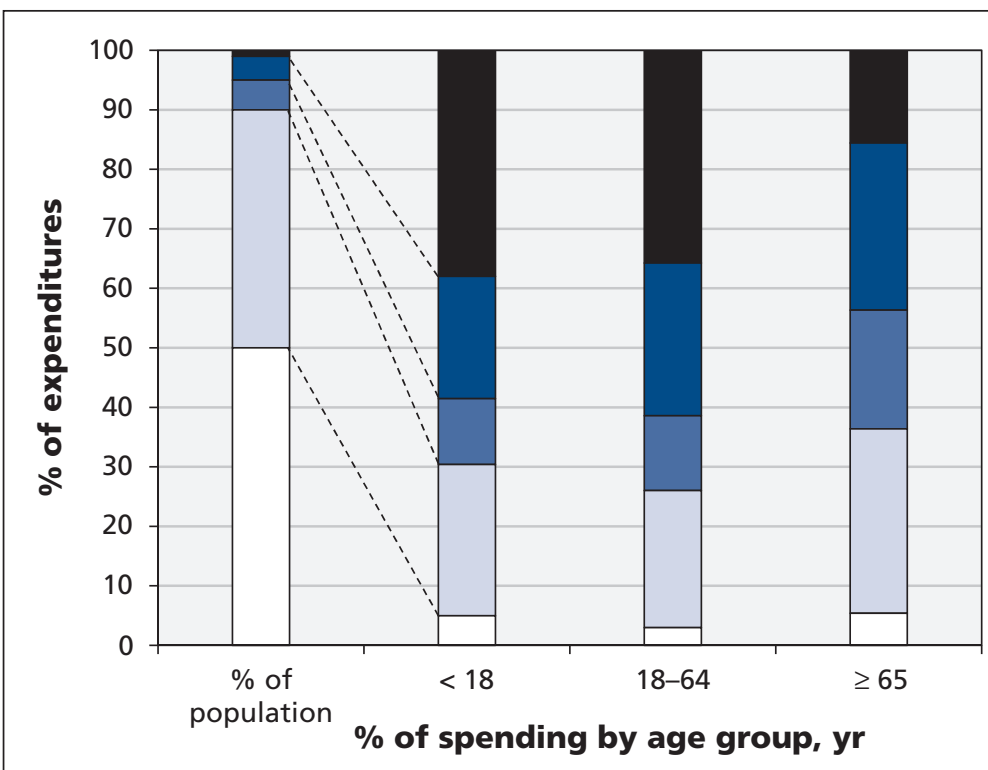

Percentile $\square<50$ th $\square$ 50th-89th $\square$ 90th-94th $\square$ 95th-98th 99th

Figure 3: Distribution of total expenditures across cost percentiles $(<50$ th, 50th89th, 90th-94th, 95th-98th, 99th), by age group. The bar on the far left represents the percentiles of the study population ranked from lowest to highest cost.

Table 2: Distribution of cost thresholds per person across cost categories, by age group

\begin{tabular}{|lrrrr|}
\hline & \multicolumn{4}{c|}{ Age group, yr; cost threshold, \$ } \\
\cline { 2 - 5 } Cost cateory & \multicolumn{1}{c|}{ All } & $<18$ & $18-64$ & $\geq 65$ \\
\hline Top $1 \%$ & 44906 & 8383 & 22070 & 83039 \\
\hline Top $5 \%$ & 7961 & 2329 & 5446 & 45203 \\
\hline Top $10 \%$ & 3815 & 1281 & 2610 & 22508 \\
\hline Median & 333 & 195 & 298 & 2211 \\
\hline
\end{tabular}

2011/12 overall and by age group (Appendix 3, available at www.cmaj.ca/lookup/suppl/doi: 10.1503/cmaj.150064/-/DC1). Among children in the top $1 \%$ cost group, the most frequent diagnoses included preterm birth, cancer and mental health disorders. Adults had a broad array of chronic diseases and infections. Among older adults, the most frequent diagnoses were chronic diseases such as heart failure and chronic obstructive pulmonary disorder or acute events such as hip fracture and stroke.

\section{Interpretation}

This study examined an exhaustive array of health care services paid for by the Ontario government, which account for about $75 \%$ of total government health expenditures. Our findings provide a comprehensive summary of health care spending in a primarily government-funded health care system. Our analyses showed moderate stability in health care costs for individuals over a 3-year period. About $45 \%$ of people in the top 5\% cost group in 2009 remained high-cost users in the subsequent year, and one-third remained at that level for all 3 years. Less than $1 \%$ of people who began in the bottom 50\% cost group transitioned to the top 5\% in the subsequent year. The sustained nature of high-cost use suggests that effective interventions to manage care among existing high-cost users may be easier to target than interventions aimed at preventing increased costs among potential highcost users.

Our results align well with prior crosssectional analyses of hospital, physician and other health sector utilization. The concentration of total health care costs among people in the top 5\% cost group is comparable to that of hospital or physician services previously described in Canada ${ }^{2,3,11}$ and is more concentrated than in the US. ${ }^{1}$ The sustained costs of care described in our analyses of multi-year spending patterns are also supported by previous studies. Both Can$\operatorname{adian}^{2,11}$ and American ${ }^{1}$ studies have shown that about $40 \%$ of older adults at the highest cost levels stayed there in the subsequent year. This congruency suggests that the patterns we observed may be similar to those experienced in other modern health care systems. We extended analyses to cover almost all patient-specific encounters in the health care system and described trajectories of patients over 3 years. We also provided new information about differences in high-cost spending patterns and conditions among different age groups.

Our study provides a comprehensive, but still incomplete picture of health care spending. Health care spending in Ontario in 2009 was $\$ 42$ billion. 
The costs included in our study amounted to $\$ 30.5$ billion, or about $75 \%$ of total government health expenditures. Most of the remaining health care spending was for public health, community service agencies and many other programs, as well as for administrative (government) staff. We estimate that about $92 \%$ of government costs associated with services to individual patients were included in our results. Our data do not include amounts paid for by individuals or private insurers primarily for private home-care and privately insured medication costs, which understates spending for all age groups. It is expected that these costs would continue over time for the most part, increasing the stability of observed spending patterns reported here.

The Commission on the Reform of Ontario's Public Services recommended efficiencies be found in health care for high-cost users in Ontario. ${ }^{12}$ Finding efficiencies does not necessitate reducing necessary care or total health care spending. Appropriate and high-value care must not be reduced or compromised. Results from our study suggest that causes and solutions vary by age. Results from randomized controlled trials of integrated care programs have had success primarily among high-risk older adults. ${ }^{13-16}$ But integrated care models are expensive and need to be targeted carefully to people who have utilization patterns that would benefit from coordination and integration over time, such as frail older patients with multiple chronic medical and functional impairments. Opportunities for cost reductions in the care of the pediatric population are quite different. The high costs from one-time neonatal care suggest that interventions should be "upstream," aimed at mothers to reduce the number and severity of premature and low-birth-weight infants. The adult population 18-64 years old who were highcost users had a disparate set of chronic disease, cancer, end-of-life care and other conditions among the 10 most common diagnoses.

Although the results presented here are striking, they do not in themselves support improvements to the health care system. A more thorough understanding of the patterns and trajectories of highcost users in the health care system, the types, timing and appropriateness of encounters and use of potentially avoidable institutional care would provide more clinical and managerial information regarding what to do to improve value and generate savings among high-cost users. The Ontario government introduced Community Health Links to better coordinate care for high-needs patients, motivated in part by findings reported here. ${ }^{17}$ Evidence suggests such transformative efforts require systematic physician engagement and leadership. ${ }^{18,19}$ Understanding the complete array of health services used by their patients is one piece of information that may help physicians to better understand where and how patients are using the health care system outside of their own practice setting. These data could be provided to physicians at the patient and practice level. Indeed, the Association of Family Health Teams of Ontario includes total system costs as calculated here in their Data to Decisions report card to Family Health Teams in Ontario. ${ }^{20}$

\section{Conclusion}

Although high health care costs were concentrated in a small minority of the population, these related to a diverse set of patient health care needs and were incurred in a wide array of health care settings. Improving the sustainability of the health care system through better management of high-cost users will require a better understanding of the clinical needs of subgroups of this population and will likely require different tactics for different high-cost populations.

\section{References}

1. Cohen S, Yu W. The concentration and persistence in the level of health expenditures over time: estimates for the US population, 2008-2009. Statistical brief no. 354; Medical Expenditures Panel Survey. Rockville (MD): Agency for Healthcare Research and Quality; 2012. Available: http://meps.ahrq.gov/mepsweb/data_ files/publications/st354/stat354.pdf (accessed 2013 Dec. 15).

2. Roos NP, Shapiro E, Tate R. Does a small minority of elderly account for a majority of health care expenditures? A sixteeenyear perspective. Milbank $Q$ 1989;67:347-69.

3. Reid R, Evans R, Barer M, et al. Conspicuous consumption: characterizing high users of physician services in one Canadian province. J Health Serv Res Policy 2003;8:215-24.

4. Ideas and opportunities for bending the health care cost curve: advice for the Government of Ontario. Toronto: Ontario Hospital Association/Ontario Federation of Community Mental Health and Addiction Programs/Ontario Association for Community Care Access Centres; 2010.

5. Deaths and mortality rate, by selected grouped causes, age group and sex, Canada, annual, CANSIM [Table 102-0551]. Ottawa: Statistics Canada; 2015.

6. Hirth RA, Gibson TB, Levy HG, et al. New evidence on the persistence of health spending. Med Care Res Rev 2015;72:277-97.

7. Johnson TL, Rinehart DJ, Durfee J, et al. For many patients who use large amounts of health care services, the need is intense yet temporary. Health Affairs 2015;34:1312-9.

8. Bronskill SE, Anderson GM, Sykora K, et al. Neuroleptic drug therapy in older adults newly admitted to nursing homes: incidence, dose and specialist contact. J Am Geriatr Soc 2004;52:749-55.

9. Wodchis W, Bushmeneva K, Nikitovic M, et al. Guidelines on person-level costing using administrative databases in Ontario: working paper series volume 1 May 2013. Toronto: Health System Performance Research Network; 2013

10. Henry D, Schultz S, Glazier R, et al. Payments to Ontario physicians from Ministry of Health and Long-Term Care sources, 1992/93 to 2009/10. Toronto: Institute for Clinical Evaluative Sciences; 2012.

11. Forget EL, Roos L, Deber R, et al. Variations in lifetime healthcare costs across a population. Healthc Policy 2008;4:e148-67.

12. Public services for Ontarians: a path to sustainability and excellence. Toronto: Commission on the Reform of Ontario's Public Services; 2012:161-2.

13. Counsell SR, Callahan C, Clark D, et al. Geriatric care management for low-income seniors: a randomized controlled trial. JAMA 2007;298:2623-33.

14. Counsell SR, Callahan CM, Buttar AB, et al. Geriatric Resources for Assessment and Care of Elders (GRACE): a new model of primary care for low-income seniors. J Am Geriatr Soc 2006; 54:1136-41

15. Béland F, Bergman H, Lebel P, et al. Integrated services for frail 
elders (SIPA): a trial of a model for Canada. Can J Aging 2006; 25:5-42.

16. Boult C, Reider L, Leff B, et al. The effect of guided care teams on the use of health services: results from a cluster-randomized trial. Arch Intern Med 2011;171:460-6.

17. Transforming Ontario's health care system: Community Health Links provide coordinated, efficient and effective care to patients with complex needs. Toronto: Ontario Ministry of Health and Long-Term Care; 2014. Available: www.health.gov.on.ca/en/pro/ programs/transformation/community.aspx (accessed 2015 Jan. 16).

18. Emanuel EJ. Where are the health care cost savings? JAMA 2012;307:39-40.

19. Keresteci M. Health Links: physician leadership as a key to success: finding from OMA jurisdictional research. Ont Med Rev 2013;80:14-7.

20. Evidence of value: D2D 2.0 report release: AFHTO members advance primary care measurement. Toronto: Association of Family Health Teams of Ontario; 2015. Available: www.afhto.ca/highlights/ key-issues/d2d-2-0-report-release (accessed 2015 Dec. 21).

Affiliations: Institute for Health Policy Management and Evaluation (Wodchis, Austin, Henry), University of Toronto; Institute for Clinical Evaluative Sciences (Wodchis, Austin, Henry); Toronto Rehabilitation Institute (Wodchis); Dalla Lana School of Public Health (Henry), University of Toronto, Toronto, Ont.
Contributors: Walter Wodchis contributed substantially to the study concept with David Henry and to the study design with Peter Austin. Walter Wodchis was responsible for the data analysis, and all of the authors contributed to the interpretation of the data. Walter Wodchis drafted the manuscript, and Peter Austin and David Henry revised it critically for important intellectual content. All of the authors gave final approval of the version to be published and agreed to act as guarantors of the work.

Funding: This study was supported by the Institute for Clinical Evaluative Sciences (ICES), which is funded by an annual grant from the Ontario Ministry of Health and Long-Term Care (MOHLTC). Peter Austin is supported in part by a Career Investigator Award from the Heart and Stroke Foundation.

Acknowledgements: The authors acknowledge Andrew $\mathrm{Cal}-$ zavara, Ashley Corallo, Kinwah Fung and Alice Newman, who are staff at ICES, for their contributions to the development of costing algorithms and the analysis of the data.

Disclaimer: The opinions, results and conclusions reported in this paper are those of the authors and are independent from the funding sources. No endorsement by ICES or the Ontario MOHLTC is intended or should be inferred.

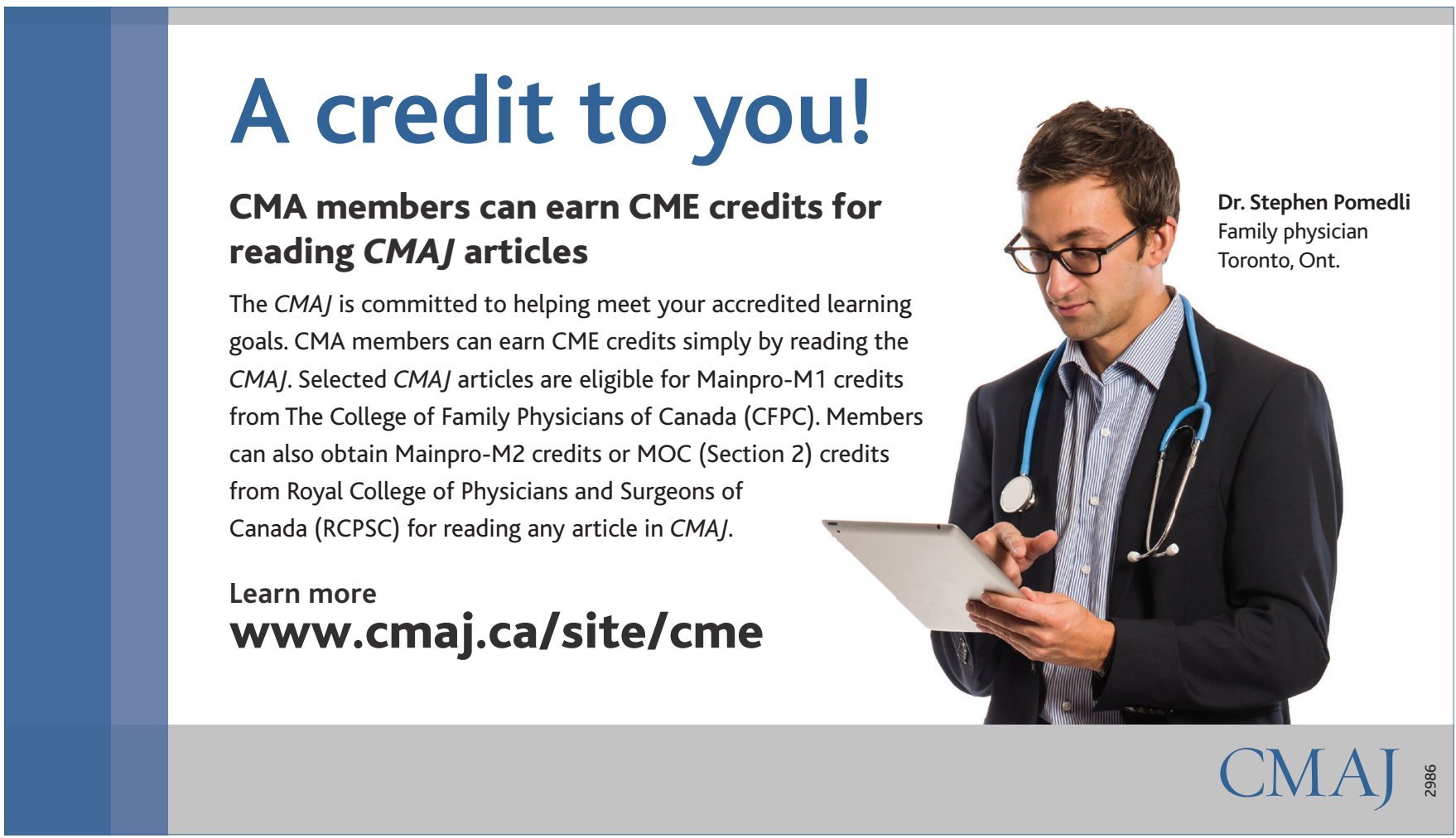

